\title{
Author Index Vol. 38, No. 3-4, 1995
}

An, P. 155 Aoki,H. 170 Beyer-Finkler, E. 173 Buetow,K. 155 Cartier,L. 238 Chen,G. 155

Evans, A.A. 155 Farrell,PJ. 195 Fujii,M. 221 Gao,L. 155 Gerlich,W.H. 143 Girardi,F. 173

Hakura,A. 181 Hasumi,K. 192 Hilger,C. 127 Hino,O. 125,170 Hirai,Y. 192 Homer, D. 195

Kajino,K. 170 Kanda,T. 187 Katase,K. 187,192 Kawanishi, M. 206 Koike, K. 134 Kondoh,G

181 Kuroiwa,Y. 214 Lamberts, C. 127 Lewis, M. 195 Li,Q. 181

London, W.T. 155 Lustbader, E. 155 McGlynn, K. 155 Meng,X.-B. 221 Onda,T. 187 Pan,J. 181

Pfíster,H. 173 Ross, E. 155 Schaefer,S. 143 Schroder, C.H. 127 Seiki,M. 221 Shen,F. 155

Shimizu,N. 214 Shimotohno, K. 162 Sillem, M. 173 Tajima,K. 238 Takada,K. 214

Takahashi,H. 187 Tanabe-Tochikura, A. 214 Teshima,H. 187,192 Tsuchiya, H. 221 Umezawa,

S. 187 Velhagen,I. 127 Watabe,H. 187 Yoshiike,K. 187 Yoshiki,T. 229 Zentgraf,H. 127 